\title{
Assessment of the orbit morphometry on West Anatolian dry skulls
}

\author{
G.N. Yonguc ${ }^{1 *}$, N. Gocmen-Mas ${ }^{1 *}$, F. Aksu1, M. Edizer¹, S.P. Akyer², S. Karabekir ${ }^{3}$ \\ ${ }^{1}$ Department of Anatomy, Faculty of Medicine, Dokuz Eylul University, Izmir, Turkey \\ 2Department of Anatomy, Faculty of Medicine, Pamukkale University, Denizli, Turkey \\ ${ }^{3}$ Department of Neurosurgery, Faculty of Medicine, Dokuz Eylul University, Izmir, Turkey
}

[Received: 14 April 2017; Accepted: 31 May 2017]

The orbit is very frequently damaged by traumas which result in not only bone deficits, but also functional deformities if reconstruction is not appropriate. Anatomical exposure of the bony orbit is of importance for both anatomists and surgeons who perform operation on this area. The current study evaluated the group of morphometrical parameters on 74 adult West Anatolian dry skulls and stereological surface area on the dry skull orbits while describing the clinical importance. Surface areas on the orbital base of the skulls were also evaluated using stereological method, bilaterally. Anthropological assessment of orbital base (in terms of width and height) revealed no significant difference between right and left sides. Both width and height of the optic foramen were significantly higher on the right side compared to left. The distances between the margins (medial, lateral, superior, inferior) of the orbital base and the optic foramen were longer on the right side compared to left, except the distances between the lateral margins. There was no significant difference among the subjects between right and left sides with respect to the orbital base in terms of stereological area calculation. The results are significant because there are no recorded anatomical data on West Anatolian skulls at previous researches. (Folia Morphol 2018; 77, 1: 105-109)

Key words: orbit, morphometry, asymmetry, skull, stereology

\section{INTRODUCTION}

The orbit carries main value in terms of the ocular bulb, skeletal and nervous system, the brain and also as the sensory organ. Multidisciplinary surgeries, such as plastic and reconstructive surgery, ophthalmology, neurosurgery etc., deal with the orbital area. Therefore, anatomical features of the orbit are of importance for these disciplines. Classically, the orbit is formed by a roof, a floor, medial and lateral walls, a base (an orbital opening) and apex. The upper wall is a thin, frontal plate which is situated largely between the orbital content and the brain contained in the anterior cranial fossa. The orbital shape is like a cone in which the apex is defined as the optic foramen. The optic canal floor, in which the optic nerve transmits, lies on at the junction of orbital roof and medial wall. The medial wall is composed by the lacrimal, the orbital part of the frontal and the orbital plate of the ethmoid bones. The lower wall is thin and largely roofs the maxillary sinus. The lateral wall is formed by the orbital face of the greater wing of the sphenoid and ventrally by frontal process of the zygomatic bone [19, 26]. The anatomy of orbital bones may be affected by

Address for correspondence: Dr. N. Gocmen-Mas, Department of Anatomy, Faculty of Medicine, Dokuz Eylul University, Izmir, Turkey, tel: +902324124372, e-mail: nuketmas@gmail.com

*The contribution of first two authors into the work was equal and higher than rest of the authors. 
several developmental or acquired pathologies. In literature, there is restricted data about a pattern for bone orbit asymmetry in dry bones. The asymmetry of the skull facial portion may be easily evaluated through a frontal view [28]. Several techniques have been described to evaluate face asymmetry as area or volume measurements were used via many methods such as planimetric method, thresholding, tracing, 3-dimensional method, software analysis systems and stereology. The point counting and planimetry are two methods for estimating the volume based on the Cavalieri principle which is known as stereology $[1,4,15,22,27]$. The stereological methods are believed to be more reliable, cheap, unbiased and effective when compared to the nonstereological methods used in the analysis of biological structures [31, 32].

Thus, we aimed to obtain morphometrical results of the orbital base and optic foramen and also stereological assessment of bilateral surface area on the orbital base to present anatomical and asymmetrical evaluation.

\section{MATERIALS AND METHODS}

The materials for the study consisted of 74 adult human dry skulls obtained from West Anatolian region which were collected randomly from the Anatomy Laboratories of Dokuz Eylul and Pamukkale Universities of Medicine Faculties. 148 of orbits were measured that belonged to West Anatolians with unknown gender and age. None of the material indicated signs of prior skull surgery, bony malformation or trauma. All bones were accepted as adults, regarding tooth eruption of the crania. Crania with orbital bone deformity were excluded. The orbit lengths were measured with the Vernier calliper as millimetres. All measurements were taken by two researchers. Anthropometric measurements on the orbits were performed using sliding callipers as centimetres with two decimals. Following parameters were investigated using metric system: At anterior aspect of the orbit following measurements were performed bilaterally: orbital base and optic foramen measurements: (1) orbital base width - the distance between the zygomaticofrontal suture and frontonasal suture; (2) orbital base height - obtained as a vertical line from the zygomaticomaxillary suture reaching the superior orbital margin; (3) optic foramen width - the widest distance between the lateral and medial margins of the foramen; (4) optic foramen height - the widest distance between the superior and inferior margins of the foramen; orbital depth measurements: (5) distance between the orbital base where frontal, lacrimal and maxillary bones jointed each other and the medial edge of the optic foramen (medial to medial); (6) distance between the orbital base - at junction of lateral margin of the orbit with zygomaticofrontal suture - and the lateral edge of the optic foramen (lateral to lateral); (7) distance between the orbital base at the level of supraorbital notch/foramen - and the upper edge of the optic foramen (superior to superior); (8) distance between the orbital base at the level of zygomaticomaxillary suture - and the lower edge of and optic foramen (inferior to inferior); (9) index for orbital base asymmetry; and (10) stereological assessment of the orbital base area in $\mathrm{cm}^{2}$ (Figs. 1, 2).

Orbital base measurements as width and height were converted into a percentage asymmetry index according to the following formula $[25,28]$ : Asymmetry index $=$ right side - left side $/$ right side $\times 100$.

The right-side value was used as a reference, negative measurement values accepted as the left side bigger than the right side. The minus value was not considered for the statistical analysis [25].

Using stereological method, an optimal plan is taken as the smallest diameter of anisotropic structures like orbital base that may be measured [14, 18]. A uniform point-grid with a point associated area of $0.25 \mathrm{~cm}^{2}$ was randomly superimposed on each orbital base of dry skull, bilaterally. To obtain surface area of orbital base using stereological technique, the point counts are converted into section areas by multiplying the total number of counted points by the square of the sequential two points distance $[2,6,16]$.

\section{Statistical analysis}

Results have been expressed as number of observations ( $n$ ) and mean \pm standard deviation (SD). All statistical analyses were performed with the SPSS software (Statistical Package for the Social Sciences, version 15.0, SSPS Inc., Chicago, IL, USA). Kolmogorov-Smirnov test was used for testing the normality of the distribution. A $p$ value less than 0.05 was considered as statistically significant. The Paired Samples $T$ test was used to compare right and left sides for data with normal distribution. 


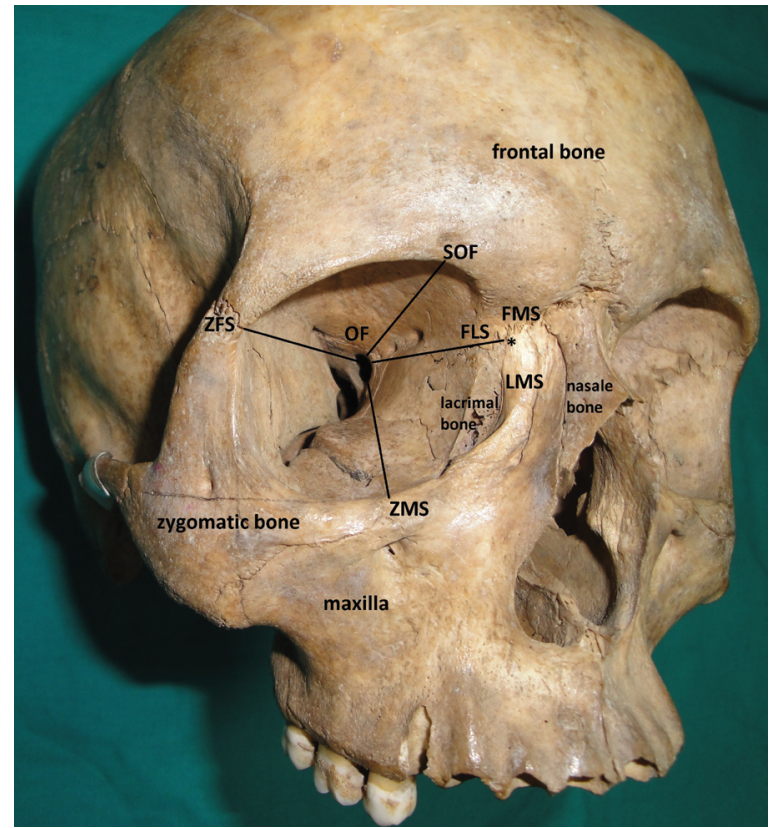

Figure 1. A representative image showing the distances (orbital depth) (superior to superior, medial to medial, inferior to inferior and lateral to lateral) between orbital opening and optic foramen; OF — optic foramen; SOF — supraorbital foramen; FMS frontomaxillary suture; FLS — frontolacrimal suture; LMS lacrimomaxillary suture; ZMS — zygomaticomaxillary suture; ZFS - zygomaticofrontal suture; *the point where frontal, lacrimal and maxillary bones jointed each other.

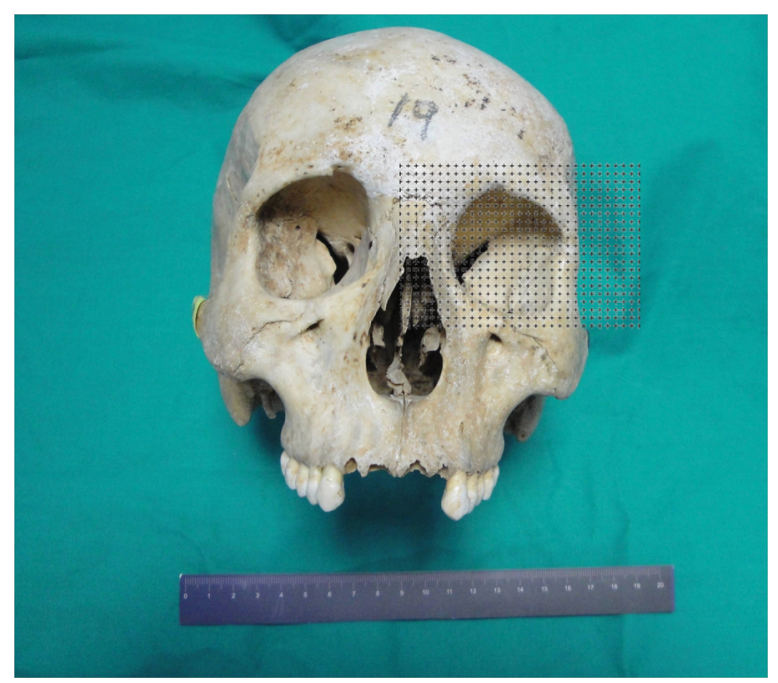

Figure 2. A representative image showing the stereological assessment of the orbital opening which is measured by using a point grid.

\section{RESULTS}

All results are presented in Table 1. Asymmetry index of the data on orbital base width and height were between (mean \pm SD) $2.59 \pm 2.41 \%$ and $3.58 \pm 2.87 \%$, respectively. All parameters of the orbits were higher on the right side than on the left. According to statistical analysis, there were no significant differences among the subjects with respect to the orbital base width and height measurements ( $p>0.05$ for both). On the other hand, both width and height of the optic foramen were higher on the right side and analysis revealed statistically significant differences $(p<0.05$ for both). The distances between the medial, lateral, superior, inferior margins of the orbital base and the optic foramen were longer on the right side than left. Statistical analysis revealed significant differences between the right and left sides $(p<0.05$ for all), except the distance between lateral borders of the orbital base and the optic foramen (lateral to lateral; $p>0.05$ ).

\section{DISCUSSION}

Evaluation of the orbit is of value in many clinical specialties including ophthalmology, optometry, oculoplastic surgery, and traumatology. Primary orbital bone tumours were reported to comprise $0.6 \%$ to $2.0 \%$ of all orbital tumours [29]. Karabekir et al. [19] also investigated 588 cranioorbital fractures following blunt trauma and evaluated with regard to aetiology, the anatomical aspect and surgical therapy. They advised that the treatment of orbit injuries required consultation with ophthalmologic, neurosurgical, plastic and maxillofacial surgeons [19]. Several authors claimed that fractures of the orbit should be approached with caution because of its complex bone organisation and also content. The orbit has critical value for clinicians during trauma and or tumour surgery $[10,19]$.

Morphometrical analysis of the orbit includes a large range of measurements including numbers, length, surface area, volume, angles, and curvature. The skull asymmetries may be defined as differences in the size or shape of each bone, as well as the positional differences of one or more bones [9, 23, 28, 30]. Sieji et al. [28] and Rossi et al. [25] claimed that, in order to evaluate the asymmetries referring to different sizes of the analysed craniofacial bones, the results were converted and expressed as percentage rate. According to Seiji et al. [28], asymmetrical differences between the orbits expressed in percentage as metric differences were around $2 \%$ to $4 \%$, which was assumed as a normal 
Table 1. Comparison of orbital measurements between the two sides

\begin{tabular}{|c|c|c|c|}
\hline Parameters & $\begin{array}{l}\text { Right (mean } \pm \text { SD) } \\
\qquad N=74\end{array}$ & $\begin{array}{l}\text { Left (mean } \pm \text { SD) } \\
\qquad N=74\end{array}$ & $\mathbf{p}$ \\
\hline Orbital base width [cm] & $3.71 \pm 0.35$ & $3.70 \pm 0.34$ & $>0.05$ \\
\hline Orbital base height [cm] & $3.44 \pm 0.23$ & $3.41 \pm 0.22$ & $>0.05$ \\
\hline Optic foramen width* [cm] & $0.52 \pm 0.06$ & $0.49 \pm 0.05$ & 0.000 \\
\hline Optic foramen height* $\left.{ }^{*} \mathrm{~cm}\right]$ & $0.61 \pm 0.05$ & $0.59 \pm 0.07$ & 0.005 \\
\hline Medial to medial* [cm] & $3.96 \pm 0.31$ & $3.89 \pm 0.36$ & 0.039 \\
\hline Lateral to lateral [cm] & $4.56 \pm 0.27$ & $4.52 \pm 0.27$ & $>0.05$ \\
\hline Superior to superior* $[\mathrm{cm}]$ & $4.51 \pm 0.31$ & $4.45 \pm 0.30$ & 0.003 \\
\hline Inferior to inferior* $[\mathrm{cm}]$ & $4.83 \pm 0.36$ & $4.70 \pm 0.37$ & 0.000 \\
\hline Orbital area $\left[\mathrm{cm}^{2}\right]$ & $10.73 \pm 1.15$ & $10.65 \pm 1.15$ & $>0.05$ \\
\hline
\end{tabular}

${ }^{*} p<0.05 ; S D$ - standard deviation

level. Similar with the authors, our data on asymmetric index of the orbit base were in normative range. Orbital morphology and asymmetry were frequently studied and many methods were used to evaluate this issue $[9,30]$. Chebib and Chamma [9] declared that the right side of the face is bigger than the left. On the other hand, they did not note any disharmony, important distortion and also did not reveal differences in orbits [9]. Ferrario et al. [13] carried out a morphometric study using face photography, where reference points were demarcated, digitalized and measured. Ezaldein et al. [12] investigated the orbital dysmorphology and deformity in patients with metopic synostosis compared with age and gender matched healthy subjects, using three-dimensional analysis.

The optic foramen may have a shape similar to a keyhole (the so-called keyhole anomaly present in $3.3 \%$ of the cases) or it may be double as a variation [5]. Magden and Kaynak [21] encountered $0.27 \%$ bilateral and $0.27 \%$ unilateral duplication of the optic canal. Patil et al. [24] found that the duplication was bilateral in $0.94 \%$ skulls, unilateral in $2.5 \%$ skulls. However, in the present study, we did not encounter any duplication of the optic foramina. The reason for this result may be our restricted sample size.

Although several studies are available about morphometrical evaluation of the orbit on dry bone material or radiographic materials and also its volumetrical assessment, there is no data about surface area calculation of orbital base using stereological technique $[3,7,8,11,17,20,31]$. Morphometry includes a large range of measurements including numbers, length, surface area, volume, angles, and curvature. The results, technique of study and clinical relevance were discussed. Seiji et al. [28] evaluated and quantified orbit asymmetry in a dry skull sample divided into different age groups using a method of digital image analysis. In the present study, orbital base surface area and the other morphometrical parameters were primarily evaluated using the stereological method. The stereology that estimates surface area using formula depending on point counting method is basic, unbiased, cheap and accurate compared with non-stereological methods [14]. To our knowledge, no previous work has defined the accuracy, reliability and repeatability of stereological technique in the measurement of orbital base area.

The limitations of our study are restricted sample size, unknown age and sex of the dry skulls. Additionally, restricted samples' variety due to the fact that they were only collected from the West Anatolian region is another limitation.

\section{CONCLUSIONS}

The current data are especially valuable because there are no similar researches aimed at assessing West Anatolian skulls in respect to the orbit. Anatomical knowledge about the orbit is important for those doing surgery in order to avoid injuring related neurovascular structures.

\section{REFERENCES}

1. Acer N, Sahin B, Usanmaz M, et al. Comparison of point counting and planimetry methods for the assessment of cerebellar volume in human using magnetic resonance imaging: a stereological study. Surg Radiol Anat. 2008; 
30(4): 335-339, doi: 10.1007/s00276-008-0330-9, indexed in Pubmed: 18292960.

2. Altunkaynak B, Onger M, Altunkaynak M, et al. A Brief Introduction to Stereology and Sampling Strategies: Basic Concepts of Stereology. NeuroQuantology. 2011; 10(1), doi: 10.14704/nq.2012.10.1.427.

3. Barone $C M$, Jimenez DF, Laskey $A$, et al. Bony orbital distances among the Filipino population. J Craniofac Surg. 2002; 13(2): 258-261, indexed in Pubmed: 12000883.

4. Bas O, Acer N, Mas N, et al. Stereological evaluation of the volume and volume fraction of intracranial structures in magnetic resonance images of patients with Alzheimer's disease. Ann Anat. 2009; 191(2): 186-195, doi: 10.1016/j.aanat.2008.12.003, indexed in Pubmed: 19269145.

5. Berlis A, Putz R, Schumacher M. [Measurements and variations in the region of the optic canal. CT and anatomy]. Radiologe. 1992; 32(9): 436-440, indexed in Pubmed: 1438728.

6. Canan S, Şahin B, Odacı E, et al. Estimation of the reference volume, volume density and volume ratios by a stereological method: Cavalieri's principle. T Klin J Med Sci. 2002; 22: 7-14.

7. Carls FR, Josca R, Sailer HF. [The measurement of orbital volume in reconstruction of the orbital walls]. Minerva Stomatol. 1996; 45(11): 493-499, doi: 10.1167/iovs.050816, indexed in Pubmed: 9026695.

8. Charteris DG, Chan $\mathrm{CH}$, Whitehouse RW, et al. Orbital volume measurement in the management of pure blowout fractures of the orbital floor. Br J Ophthalmol. 1993; 77(2): 100-102, doi: 10.1136/bjo.77.2.100, indexed in Pubmed: 8435407.

9. Chebib FS, Chamma AM. Indices of craniofacial asymmetry. Angle Orthod. 1981; 51(3): 214-226, doi: 10.1043/ /0003-3219(1981)051<0214:IOCA > 2.0.CO;2, indexed in Pubmed: 6943950.

10. Cook T. Ocular and periocular injuries from orbital fractures. J Am Coll Surg. 2002; 195(6): 831-834, indexed in Pubmed: 12495316.

11. Deveci M, Oztürk S, Sengezer M, et al. Measurement of orbital volume by a 3-dimensional software program: an experimental study. J Oral Maxillofac Surg. 2000; 58(6): 645-648, indexed in Pubmed: 10847286.

12. Ezaldein HH, Metzler P, Persing JA, et al. Three-dimensional orbital dysmorphology in metopic synostosis. J Plast Reconstr Aesthet Surg. 2014; 67(7): 900-905, doi: 10.1016/j. bjps.2014.03.009, indexed in Pubmed: 24820454.

13. Ferrario VF, Sforza C, Miani A, et al. Craniofacial morphometry by photographic evaluations. Am J Orthod Dentofacial Orthop. 1993; 103(4): 327-337, doi: 10.1016/08895406(93)70013-E, indexed in Pubmed: 8480698.

14. Gocmen-Mas N, Pelin C, Canan S, et al. Stereological evaluation of volumetric asymmetry in healthy human cerebellum. Surg Radiol Anat. 2009; 31(3): 177-181, doi: 10.1007/s00276-008-0424-4, indexed in Pubmed: 18941706.

15. Gong QY, Tan LT, Romaniuk CS, et al. Determination of tumour regression rates during radiotherapy for cervical carcinoma by serial MRI: comparison of two measurement techniques and examination of intraobserver and interobserver variability. $\mathrm{Br} J$ Radiol. 1999; 72(853): 62-72, doi: 10.1259/bjr.72.853.10341691, indexed in Pubmed: 10341691.

16. Gundersen $H$, Bendtsen TF, Korbo L, et al. Some new, simple and efficient stereological methods and their use in pathological research and diagnosis. APMIS. 1988; 96(1-6): 379-394, doi: 10.1111/j.1699-0463.1988. tb05320.x.
17. Ji Y, Qian Z, Dong Y, et al. Quantitative morphometry of the orbit in Chinese adults based on a three-dimensional reconstruction method. J Anat. 2010; 217(5): 501-506, doi: 10.1111/j.1469-7580.2010.01286.x, indexed in Pubmed: 20807268.

18. Kahveci OK, Gocmen-Mas N, Okur N, et al. Investigation of temporal bone asymmetry in cases with unilateral tinnitus: morphometric and multicentric clinical study. Folia Morphol. 2013; 72(1): 22-28, doi: 10.5603/FM.2013.0004, indexed in Pubmed: 23749707.

19. Karabekir HS, Gocmen-Mas N, Emel E, et al. Ocular and periocular injuries associated with an isolated orbital fracture depending on a blunt cranial trauma: anatomical and surgical aspects. J Craniomaxillofac Surg. 2012; 40(7): e189-e193, doi: 10.1016/j.jcms.2011.10.006, indexed in Pubmed: 22093244.

20. Lukats O, Vízkelety T, Markella Z, et al. Measurement of orbital volume after enucleation and orbital implantation. PLoS One. 2012; 7(12): e50333, doi: 10.1371/journal. pone.0050333, indexed in Pubmed: 23236368.

21. Mağden A, Kaynak S. Bilateral duplication of the optic canals. Ann Anat. 1996; 178(1): 61-64, indexed in Pubmed: 8717328.

22. McEvoy F. An application of image processing techniques in computed tomography image analysis. Vet Radiol Ultrasound. 2007; 48(6): 528-534, doi: 10.1111/j.17408261.2007.00290.x.

23. Mulick JF. An investigation of craniofacial asymmetry using the serial twin-study method. Am J Orthod. 1965; 51: 112-129, doi: 10.1016/0002-9416(65)90165-X, indexed in Pubmed: 14232060.

24. Patil GV, Kolagi S, Padmavathi G, et al. The duplication of the optic canals in human skulls. J Clin Diagn Res. 2011; 5: 536-537.

25. Rossi M, Ribeiro E, Smith R. Craniofacial asymmetry in development: an anatomical study. Angle Orthod. 2003; 73(4): 381-385, doi: 10.1043/0003-3219(2003)073<0381:CAIDAA>2.0.CO;2, indexed in Pubmed: 12940558.

26. Ruskell GL. The orbit and its content. Chapter 41. In: Standring S (Chief ed.). Gray's anatomy head and neck. 39th ed. Edinburgh; New York: Elsevier Churchill Livingstone. 2005: 681-700.

27. Sahin B, Ergur H. Assessment of the optimum section thickness for the estimation of liver volume using magnetic resonance images: a stereological gold standard study. Eur J Radiol. 2006; 57(1): 96-101, doi: 10.1016/j. ejrad.2005.07.006, indexed in Pubmed: 16112829.

28. Seiji F, Moreira RS, De Angelis MA, et al. Orbital asymmetry in development: an anatomical study. Orbit. 2009; 28(6): 342-346, doi: 10.3109/01676830903162841, indexed in Pubmed: 19929657.

29. Selva D, White VA, O'Connell JX, et al. Primary bone tumors of the orbit. Surv Ophthalmol. 2004; 49(3): 328-342, doi: 10.1016/j.survophthal.2004.02.011, indexed in Pubmed: 15110669.

30. Shah SM, Joshi MR. An assessment of asymmetry in the normal craniofacial complex. Angle Orthod. 1978; 48(2): 141-148, doi: 10.1043/0003-3219(1978)048<0141:AAO AIT>2.0.CO;2, indexed in Pubmed: 277077.

31. West MJ, Slomianka L, Gundersen HJ. Unbiased stereological estimation of the total number of neurons in thesubdivisions of the rat hippocampus using the optical fractionator. Anat Rec. 1991; 231(4): 482-497, doi: 10.1002/ ar.1092310411, indexed in Pubmed: 1793176.

32. Yilmaz I, Adiguzel E, Akdogan I, et al. Effects of second generation tetracyclines on penicillin-epilepsy-induced hippocampal neuronal loss and motor incoordination in rats. Life Sci. 2006; 79(8): 784-790, doi: 10.1016/j. Ifs.2006.02.027, indexed in Pubmed: 16554072 